\title{
Face perception in autism spectrum disorder: modulation of holistic processing by facial emotion
}

Article

Accepted Version

Creative Commons: Attribution-Noncommercial-No Derivative Works 4.0

Brewer, R., Bird, G., Gray, K. L. H. and Cook, R. (2019) Face perception in autism spectrum disorder: modulation of holistic processing by facial emotion. Cognition, 193. 104016. ISSN 0010-0277 doi:

https://doi.org/10.1016/j.cognition.2019.104016 Available at https://centaur.reading.ac.uk/84116/

It is advisable to refer to the publisher's version if you intend to cite from the work. See Guidance on citing.

To link to this article DOI: http://dx.doi.org/10.1016/j.cognition.2019.104016

Publisher: Elsevier

All outputs in CentAUR are protected by Intellectual Property Rights law, including copyright law. Copyright and IPR is retained by the creators or other copyright holders. Terms and conditions for use of this material are defined in the End User Agreement.

www.reading.ac.uk/centaur 
Central Archive at the University of Reading

Reading's research outputs online 
Accepted for publication in Cognition on $6^{\text {th }}$ June 2019

\section{Face perception in autism spectrum disorder: Modulation of holistic processing by facial emotion}

Rebecca Brewer ${ }^{1 *}$, Geoffrey Bird ${ }^{2,3}$, Katie L.H. Gray ${ }^{4}, \&$ Richard Cook ${ }^{5}$

${ }^{1}$ Department of Psychology, Royal Holloway, University of London ${ }^{2}$ Experimental Psychology Department, University of Oxford ${ }^{3}$ MRC Social, Genetic \& Developmental Psychiatry Centre, King's College London ${ }^{4}$ Psychology and Clinical Language Sciences, University of Reading ${ }^{5}$ Department of Psychological Sciences, Birkbeck, University of London

*Corresponding author:

Rebecca.Brewer@rhul.ac.uk

Department of Psychology,

Royal Holloway, University of London,

Egham, Surrey, U.K.

TW20 0EX. 


\section{Highlights}

- Individuals with and without autism completed a composite face procedure

- The strength of facial emotion cues in the distractor regions was manipulated

- High-emotion distractor regions produced stronger composite face effects

- Similar modulation by facial emotion was seen in both groups

- Typical composite effects in autism suggest intact holistic face processing 


\begin{abstract}
Individuals with Autism Spectrum Disorder (ASD; autistic individuals) may exhibit atypical face perception because they fail to process faces holistically. In the context of this hypothesis, it is critical to determine whether autistic individuals exhibit diminished susceptibility to the composite face illusion, widely regarded as key marker of holistic face processing. To date, however, previous studies have yielded inconsistent findings. In light of recent evidence suggesting that facial emotion cues increase the strength of the composite face illusion in typical individuals, the present study sought to determine whether the presence of facial emotion also modulates the strength of the composite face illusion in autistic individuals, many of whom experience difficulties recognizing facial expressions. We therefore measured composite face effects in a sample of autistic individuals $(\mathrm{N}=20)$ and matched typical controls $(\mathrm{N}=29)$ using an incidental emotion procedure in which distractor regions varied systematically in their emotion strength. As expected, the presence of facial emotion in the distractor regions of composite face arrangements increased the strength of the illusory distortion induced. The extent of the modulation by facial emotion was similar in the two groups. The composite effects seen in the ASD group were qualitatively and quantitatively similar to those seen in the typical group, suggestive of intact holistic processing in this population.
\end{abstract}

Keywords: Autism Spectrum Disorder; Composite face effect; Holistic face processing; Alexithymia; Emotion 


\section{Introduction}

Autism Spectrum Disorder (ASD) is a neurodevelopmental disorder characterized by difficulties with social interaction and communication, as well as restricted interests and repetitive behaviors (APA, 2013). While not a diagnostic marker of ASD, atypical face perception is also thought to be common in this population (Simmons et al., 2009; Webb, Neuhaus, \& Faja, 2016). For example, many studies have observed difficulties recognizing facial identity in individuals with ASD (Boucher \& Lewis, 1992; Hedley, Brewer, \& Young, 2011; Wallace, Coleman, \& Bailey, 2008a; Weigelt, Koldewyn, \& Kanwisher, 2012). Autistic people ${ }^{1}$ often have difficulties learning faces from multiple encounters; i.e., they derive less benefit from seeing the same face in different poses, and under differ viewing conditions, than typical observers (Ipser, Ring, Murphy, Gaigg, \& Cook, 2016). Many autistic individuals also exhibit atypical perception of facial motion (O'Brien, Spencer, Girges, Johnston, \& Hill, 2014; P. Shah, Bird, \& Cook, 2016). Where observed, atypical face perception may hamper social interaction and contribute to the emergence of the wider sociocognitive features of ASD (Klin, Schultz, \& Jones, 2015; Schultz, 2005; P. Shah, Gaule, Bird, \& Cook, 2013).

Expert face perception is thought to involve holistic processing, whereby local features are integrated into a unified whole (Farah, Wilson, Drain, \& Tanaka, 1998; Maurer, Le Grand, \& Mondloch, 2002; McKone \& Yovel, 2009; Piepers \& Robbins, 2013). Interestingly, however, people with ASD are thought to focus on local stimulus features, a tendency that may undermine their ability to form integrated global percepts (Behrmann, Thomas, \& Humphreys, 2006; Happé, 1999; Happé \& Frith, 2006). For example, those with ASD often perform well on the Embedded Figures Task, in which observers must disregard a complex global pattern in order to locate a particular local element (Ropar \& Mitchell, 2001; A. Shah \& Frith, 1983). Some evidence also suggests that autistic individuals exhibit reduced susceptibility to visual illusions induced by context (Happé, 1996; P. Shah et al., 2016), and reduced global-to-local interference when responding to ("Navon") compound letter stimuli (Behrmann, Avidan, et al., 2006; see also Koldewyn, Jiang, Weigelt, \& Kanwisher, 2013). Individuals with ASD may therefore exhibit atypical face perception because they fail to process faces holistically (Behrmann, Thomas, et al., 2006; Happé, 1999; Happé \& Frith, 2006). 
In light of this possibility, several studies have sought to determine whether autistic individuals show reduced susceptibility to the composite face illusion (Gauthier, Klaiman, \& Schultz, 2009; Nishimura, Rutherford, \& Maurer, 2008; Teunisse \& de Gelder, 2003; Ventura et al., 2018). When the upper half of one face (the target region) is aligned with the lower half of another (the distractor region), the face halves appear to 'fuse' perceptually. The illusory distortion induced by the distractor region hampers observers' ability to make perceptual judgements about the target (Hole, 1994; Young, Hellawell, \& Hay, 1987). Crucially, this composite face illusion suggests a tendency to integrate information from different facial regions, and is therefore regarded as a key marker of holistic face processing (Murphy, Gray, \& Cook, 2017; Rossion, 2013). Reduced susceptibility to the composite face illusion would therefore indicate that individuals with ASD fail to process faces holistically. Thus far, however, findings have been inconsistent; while some studies have reported atypical composite effects in ASD (Gauthier et al., 2009; Teunisse \& de Gelder, 2003), others have described typical susceptibility to the illusion (Nishimura et al., 2008; Ventura et al., 2018).

Previous studies of composite face processing in ASD (Gauthier et al., 2009; Nishimura et al., 2008; Teunisse \& de Gelder, 2003; Ventura et al., 2018) have used composite arrangements constructed from emotionally neutral faces (from photographs of actors who have been asked to convey no emotion). This is the conventional approach when using the composite face paradigm to measure individual differences in holistic processing (e.g., Konar, Bennett, \& Sekuler, 2010; Rezlescu, Susilo, Wilmer, \& Caramazza, 2017; Richler, Cheung, \& Gauthier, 2011; Wang, Li, Fang, Tian, \& Liu, 2012). However, recent work indicates that the strength of the composite face illusion is greatly increased by the presence of facial emotion cues in the distractor facial region (Gray, Murphy, Marsh, \& Cook, 2017). Emotional expressions are a strong source of correlated change across distal facial regions (Cook, Aichelburg, \& Johnston, 2015; Jack, Garrod, \& Schyns, 2014); for example, a smiling mouth predicts creases around the eyes (so-called 'eye-smile'). Emotion cues may therefore augment the binding of facial regions into integrated holistic representations (Gray, Murphy, et al., 2017; Johnston, 2011). The effect of facial emotion on the composite face illusion is so striking that even subtle expression cues present in ostensibly neutral faces (e.g., pursed lips, upturned corners of the mouth) induce significantly stronger illusory distortion when present in distractor regions (Gray, Murphy, et al., 2017). 
Notably, many studies have observed difficulties recognizing facial expressions of emotion in those with ASD (Ashwin, Chapman, Colle, \& Baron-Cohen, 2006; Harms, Martin, \& Wallace, 2010; Humphreys, Minshew, Leonard, \& Behrmann, 2007; Philip et al., 2010; Wallace, Coleman, \& Bailey, 2008b). Recent evidence suggests that these deficits may be due to the presence of co-occurring alexithymia ('the alexithymia hypothesis'; Bird \& Cook, 2013). Alexithymia is a trait associated with difficulties identifying and describing one's own emotions (Nemiah, Freyberger, \& Sifneos, 1976), that also impairs individuals' ability to recognize the emotions of others (Grynberg et al., 2012). Importantly, alexithymia co-occurs highly with ASD (for review see Poquérusse, Pastore, Dellantonio, \& Esposito, 2018). Estimates suggest that as many as $50 \%$ of autistic individuals may have clinically relevant levels of alexithymia (Berthoz \& Hill, 2005; Hill, Berthoz, \& Frith, 2004). While the alexithymia hypothesis remains a theory, empirical support for this view is accumulating (e.g. Cook, Brewer, Shah, \& Bird, 2013; Oakley, Brewer, Bird, \& Catmur, 2016).

In the present study, we examined whether emotion cues present in the distractor regions of composite face arrangements have differential effects on the composite face effects seen in typical individuals and those with ASD. Despite being constructed from ostensibly neutral faces, many widely used sets of composite face stimuli are rich in unintended emotion cues (see Murphy et al., 2017; Figure 5). Given that i) these emotion cues increase the strength of the composite face effect in typical individuals (Gray, Murphy, et al., 2017), and ii) many autistic individuals experience difficulties recognizing facial expressions (Ashwin et al., 2006; Harms et al., 2010; Humphreys et al., 2007; Philip et al., 2010; Wallace et al., 2008b), we reasoned that autistic samples may exhibit diminished composite face effects only where distractor regions contain - intended or unintended - emotion cues. In other words, autistic individuals may only show reduced composite face effects if they are less able to perceive subtle signs of emotions in the face halves used to construct composite face stimuli.

Individuals with ASD and matched typical controls completed the 'incidental' emotion composite face procedure described by Gray and colleagues (2017; Experiment 1). In this task, participants judge whether sequentially presented target regions (upper face halves) are identical or not, whilst attempting to ignore task-irrelevant distractor regions (lower face halves). The distractor regions are always cropped from different facial identities (the socalled 'original' composite procedure; Murphy et al., 2017; Rossion, 2013). Unlike standard matching procedures, however, image morphing is used to vary the emotion content of the 
distractor region, such that there are three emotion intensity conditions: 1) low emotion cues (neutral stimulus), 2) moderate emotion cues (morph of 50\% neutral stimulus, 50\% emotional stimulus), and 3) strong emotion cues (emotional stimulus). As the strength of the emotion signal increases, the strength of the composite effect increases, i.e., the distractor regions induce greater illusory distortion of the target region, and typical participants' ability to discriminate the target regions decreases (Gray, Murphy, et al., 2017). The modulatory effect of emotion intensity is eliminated when composite arrangements are misaligned, indicating that the effect is not attributable to response bias or distraction. Should autistic individuals exhibit atypical composite effects because of the increased prevalence of emotion processing difficulties in this population, the ASD group would not show increases in the size of the composite effect with greater levels of distractor emotion.

Previously, the holistic processing of facial emotion has been investigated by examining the extent to which an incongruous emotion signal in the distractor region impairs participants' ability to label the emotion depicted in the target half (Calder, Young, Keane, \& Dean, 2000). This paradigm is poorly-suited for use with autistic individuals, as many - particularly those with co-occurring alexithymia - have difficulty labelling and interpreting the emotional content of isolated local regions (Baron-Cohen, Wheelwright, \& Jolliffe, 1997; Oakley et al., 2016). In the paradigm used here, however, participants are simply required to judge whether target regions are identical or not. As there is no requirement to label the emotion in the target region, the emotion manipulation is incidental to the primary matching task.

\section{Method}

\subsection{Participants}

Twenty individuals with $\left(M_{\text {age }}=33.95 ; S D_{\text {age }}=11.39 ; 3\right.$ females $)$ and 29 individuals without $^{2}$ $\left(M_{\mathrm{age}}=35.03 ; S D_{\mathrm{age}}=10.16 ; 2\right.$ females $)$ a clinical diagnosis of ASD participated in this study. The ASD and typical groups did not differ significantly in terms of age $[t(47)=.35, p$ $=.728]$, gender $\left[X^{2}(1)=.85, p=.357\right]$, or IQ $[t(47)=.85, p=.399]$, measured by the Wechsler Adult Intelligence Scale (Wechsler, 1997) in the ASD group, and the Wechsler Abbreviated Scale of Intelligence (Wechsler, 1999) in the typical controls group. Individuals with ASD were diagnosed by an independent clinician. The Autism Diagnostic Observation Schedule (ADOS-2; Lord et al., 2000) was also used to determine individuals' current level of ASD symptom severity. Of the 20 participants with a clinical diagnosis of ASD, 12 met criteria for a classification of 'autism', and 8 met the criteria for a classification of 'autistic 
spectrum', according to the ADOS-2. The ASD group also had greater levels of autistic traits than the typical group $[t(47)=7.57, p<.001]$, assessed by the Autism-Spectrum Quotient (AQ; Baron-Cohen, Wheelwright, Skinner, Martin, \& Clubley, 2001). Detailed diagnostic information can be seen in Table 1 .

Levels of alexithymia were measured using the Toronto Alexithymia Scale (TAS-20; Bagby, Taylor, \& Parker, 1994), and completed by all autistic participants and all but one participant in the typical group. As expected, alexithymia severity was higher in the $\operatorname{ASD}(M=60.30$, $S D=14.89)$ than in the typical $(M=41.07, S D=8.14)[t(46)=5.24, p<.001]$ group. TAS20 scores ranged from 27 to 84 in the ASD group, and from 23 to 56 in the typical group. Through the application of the established cut-off, 11 members of the ASD sample were classified as having high levels of alexithymia (TAS-20 score $>60$ ), and 9 members were classified as having low levels of alexithymia (TAS-20 score $<61$ ). All typical controls were classified as having low levels of alexithymia on this basis.

\subsection{Procedure}

Composite arrangements were constructed from faces selected from the Radboud Face Database (Langner et al., 2010). Target regions (upper face halves ${ }^{3}$ ) were cropped from 18 male identities with neutral expressions. Distractor regions (lower face halves) were cropped from 3 male identities depicting happy or angry expressions, at low $(0 \%)$, moderate $(50 \%)$, and strong (100\%) intensity. The moderate intensity distractor region was created by blending the low and strong intensity expressions using Morpheus Photo Morpher Version 3.11 (Morpheus Software, Indianapolis, IN). When combined, composite face arrangements subtended approximately $6^{\circ}$ vertically when viewed from a distance of $58 \mathrm{~cm}$. Misaligned composites were created by introducing a horizontal offset of $3^{\circ}$. In both alignment conditions, a small vertical gap of $\sim 4$ pixels was placed between the face halves (see Rossion \& Retter, 2015).

Each trial began with a fixation point, followed by two composite arrangements presented sequentially for $200 \mathrm{~ms}$ each. A mask of high-contrast grey-scale ovals was presented during the $1000 \mathrm{~ms}$ inter-stimulus-interval (Figure 1). Following the offset of the second composite arrangement, participants were prompted to respond with a button press, to indicate whether the two target regions were identical or not ('same' or 'different'). In keeping with the original composite procedure, the two distractor regions used on a given trial always differed 
in their identity. The two distractors always had the same emotional intensity $(0 \%, 50 \%$, $100 \%$ ). Where an emotion signal was present, they differed in emotional content (either happy or angry). The first and second composite arrangements were equally likely to have happy and angry distractor regions. In total, there were 216 experimental trials: 18 target pairs $\times 2$ target types (same, different) $\times 2$ alignment types (aligned, misaligned) $\times 3$ levels of emotion intensity $(0 \%, 50 \%, 100 \%)$. Trial type was randomly interleaved within four blocks of 54 trials.

Figure-1

Where possible, we also assessed the face recognition ability of the autistic participants (Table 1). Nineteen of the 20 ASD participants completed the Cambridge Face Memory Test (CFMT; Duchaine \& Nakayama, 2006a) and seventeen participants with ASD completed the 20-Item Prosopagnosia Index (PI20; Shah, Gaule, Sowden, Bird, \& Cook, 2015). For comparison, the scores of the current ASD group on these measures were compared to the sample of 142 typical adult participants $\left(M_{\mathrm{age}}=29.2\right.$ years, $S D_{\mathrm{age}}=11.9$ years $)$ previously described by Gray, Bird \& Cook (2017; Experiment 1). The ASD group showed significant evidence of face recognition difficulties relative to this comparison group on both the CFMT $[t(159)=4.544, p<.001]$, and the PI20 $[t(157)=5.059, p<.001]$. Participants' scores on the PI20 and CFMT correlated significantly $(r=-61, p=.010)$.

We also measured the emotion recognition ability of 17 of the 20 autistic individuals using a binary categorization procedure (for full details see Brewer, Biotti, Bird, \& Cook, 2017). Each trial presented a single expression stimulus (1200 ms) drawn from morph-continua that blended pairs of emotional facial expressions. One continuum blended an expression that was $20 \%$ anger / $80 \%$ disgust with an expression that was $80 \%$ anger $/ 20 \%$ disgust. The other, blended an expression that was $20 \%$ fear / $80 \%$ sadness with an expression that was $80 \%$ fear $120 \%$ sadness. Each continuum comprised seven levels that varied the strength of the emotion signal in increments of $10 \%$. On each trial participants were asked to make a binary categorization judgement (was the expression best classified as disgust or anger; sadness or fear). The level of decision noise associated with their categorization judgements was inferred from the slopes of the resulting psychometric functions, whereby higher values indicate less precise emotion recognition (Table 1). 
Table-1

\section{Results}

When analyzing data from the original matching procedure, the composite face effect is evidenced by a disproportionate reduction in accuracy on 'same' target trials, relative to 'different' trials (e.g., Le Grand, Mondloch, Maurer, \& Brent, 2004). Because distractor regions differ, perceptual fusion of the distractor and target alters how observers perceive the target and makes it more difficult to see that sequentially presented target halves are identical. The detrimental effects of distractor, and any interaction with emotion, should be greatly reduced in the misaligned condition, where the composite illusion manifests less strongly.

Participants' matching accuracy (\% correct) was analyzed using ANOVA with Alignment (aligned, misaligned), Emotion Intensity (0\%, 50\%, 100\%), and Target Type (same, different) as within-participants factors, and Group (ASD, typical) as a between-participants factor (Table 2, Figure 2). This analysis revealed a significant Alignment $\times$ Target Type interaction $\left[F(1,47)=12.82, p=.001, \eta^{2}=.214\right]$ characteristic of the composite face effect. Generally, performance on same trials was worse in the aligned condition (where the illusion hampers correct responding) than in the misaligned condition (where observers are free of the illusory interference) $[t(48)=3.28, p=.002]$. In contrast, performance on different trials was better for aligned than misaligned stimuli $[t(48)=2.29, p=.027]$.

It was evident, however, that the Alignment $\times$ Target Type interaction varied as a function of Emotion Intensity $\left[F(2,94)=8.77, p<.001, \eta^{2}=.157\right]$, as observed previously by Gray and colleagues (2017). Simple Alignment $\times$ Target Type interactions were observed in the $50 \%$ emotion condition $\left[F(1,47)=11.08, p=.002, \eta^{2}=.191\right]$, and in the $100 \%$ emotion condition $\left[F(1,47)=14.54, p<.001, \eta^{2}=.236\right]$, but not in the $0 \%$ emotion condition $[F(1,47)=.016, p$ $\left.=.901, \eta^{2}<.001\right]$. The Alignment $\times$ Target Type $\times$ Emotion Intensity interaction was driven by differences between the $0 \%$ emotion condition and both the $50 \%$ emotion condition $\left[F(1,47)=10.73, p=.003, \eta^{2}=.186\right]$, and the $100 \%$ emotion condition $[F(1,47)=13.80, p=$ $\left..001, \eta^{2}=.227\right]$. The size of the composite effect was similar in the $50 \%$ and $100 \%$ emotion conditions $\left[F(1,47)=.003, p=.953, \eta^{2}<.001\right]$.

Simple contrasts indicated that, in the $0 \%$ emotion condition, there was no effect of alignment in either the same $[t(48)=1.14, p=.262]$ or different $[t(48)=1.00, p=.322]$ trials. In the 
$50 \%$ emotion condition, however, there was clear evidence of a composite effect, whereby an effect of alignment was found in the same $[t(48)=3.17, p=.003]$, but not the different $[t(48)$ $=1.60, p=.116]$, trials. A composite effect was also observed in the $100 \%$ emotion condition; there was again an effect of alignment in the same $[t(48)=4.14, p<.001]$, but not different $[t(48)=1.83, p=.074]$, trials. These significant contrasts survive Bonferroni correction (they remain significant at $\alpha=.008$ ).

Crucially, there was no evidence that ASD is associated with reduced composite effects. There was not a significant main effect of ASD group $\left[F(1,47)=2.48, p=.122, \eta^{2}=.050\right]$ and neither the Alignment $\times$ Target Type interaction $[F(1,94)=.17, p=.681]$, nor the Alignment $\times$ Target Type $\times$ Emotion Intensity interaction $\left[F(2,94)=.005, p=.995, \eta^{2}<\right.$ .001] varied as a function of Group. Similarly, Group did not interact with the size of the composite effect at any of the three levels of Emotion Intensity when considered separately (all $p s>.72$ ). The only effect of Group was an Alignment $\times$ Emotion Intensity $\times$ Group interaction $\left[F(2,94)=3.72, p=.028, \eta^{2}=.073\right]$. The ASD participants showed a trend toward better discrimination for aligned trials at $0 \%$ emotion intensity, that was not seen in the other emotion conditions $(50 \%, 100 \%)$, and was not exhibited by the typical participants at any level of emotion intensity. This effect was not predicted and is difficult to interpret with confidence. However, the lack of an interaction with Trial Type suggests it has little to do with the composite illusion itself.

Figure-2

Table-2

Next, we analyzed the data from the typical $(\mathrm{N}=29)$ and ASD $(\mathrm{N}=20)$ groups separately, using a three-way ANOVA with Alignment, Target Type, and Emotion Intensity as withinsubjects factors. The analyses revealed significant evidence of the standard composite effect (Alignment $\times$ Target Type interaction) in both the typical $\left[F(1,28)=7.09, p=.013, \eta^{2}=\right.$ $.202]$ and $\operatorname{ASD}\left[F(1,19)=5.63, p=.028, \eta^{2}=.229\right]$ groups. We observed a significant Alignment $\times$ Target Type $\times$ Emotion Intensity interaction in the typical group $[F(2,56)=$ $\left.6.46, p=.003, \eta^{2}=.187\right]$, replicating the findings of Gray et al. (2017). For the typical observers, we saw Alignment $\times$ Trial type interactions at $50 \%\left[F(1,28)=7.12, p=.013, \eta^{2}=\right.$ $.213]$, and $100 \%\left[F(1,28)=8.67, p=.006, \eta^{2}=.236\right]$ emotion intensities, but not for $0 \%$ intensity $\left[F(1,28)=.05, p=.824, \eta^{2}=.002\right]$. The Alignment $\times$ Target Type $\times$ Emotion 
Intensity interaction also approached significance in the ASD group $[F(2,38)=2.97, p=$ $\left..063, \eta^{2}=.135\right]$. The autistic observers exhibited a strong trend for the Alignment $\times$ Trial type interaction at $50 \%$ emotion intensity $\left[F(1,19)=4.24, p=.053, \eta^{2}=.182\right]$, and a significant Alignment $\times$ Trial type interaction at $100 \%$ intensity $[F(1,19)=6.05, p=$ $\left..024, \eta^{2}=.241\right]$, but not for $0 \%$ intensity $\left[F(1,19)=.10, p=.761, \eta^{2}=.005\right]$. Thus, the pattern of results was very similar in the two groups separately.

Finally, we sought to examine whether face recognition ability, emotion categorization ability, and alexithymia, were related to individual differences in composite effect susceptibility. In the past, different authors have used different methods to quantify the strength of the effect shown by individual participants. However, having utilised three different methods of quantifying the effect, we found no relationship between individuals' susceptibility and their PI20 scores (all $r \mathrm{~s}<.27$, all $p \mathrm{~s}>.31$ ), their CFMT scores (all $r \mathrm{~s}<.42$, all $p \mathrm{~s}>.075)$, their emotion categorization decision noise (all $r \mathrm{~s}<.39$, all $p \mathrm{~s}>.13$ ), or their score on the TAS-20 scores (all $r \mathrm{~s}<.35$, all $p \mathrm{~s}>.135$ ). A full description of the correlational analyses is provided as supplementary online material.

\section{Discussion}

The current study sought to determine whether facial emotion cues differentially modulate the strength of the composite face illusion in typical individuals and those with ASD. Given that difficulties recognizing and interpreting facial emotion are more common in individuals with ASD than those without ASD and previous findings suggest that the strength of composite face effects are greatly influenced by the presence of unintended emotion cues in composite arrangements (Gray, Murphy, et al., 2017), we reasoned that individuals with ASD may exhibit atypical composite face effects where distractor regions are rich in emotion cues. Having measured composite effects using distractor regions that varied systematically in their emotion strength, we found no evidence for this possibility; individuals with and without ASD showed extremely similar composite face effects at intermediate and strong levels of distractor emotion. As expected, the composite effects seen in both groups were eliminated when the distractor and target regions were misaligned, indicating that the effects observed were both quantitatively and qualitatively similar. Notably, individual differences in composite effect susceptibility seen in the autistic individuals were unrelated to their level of alexithymia or emotion categorization ability. 


\subsection{Implications for social perception in ASD}

There has been considerable speculation that a failure to process faces holistically may underlie the face perception deficits seen in ASD (Behrmann, Avidan, et al., 2006;

Behrmann, Thomas, et al., 2006; Happé, 1999; Happé \& Frith, 2006). In this context, it is critical to determine whether autistic individuals exhibit diminished susceptibility to the composite face illusion, regarded as a key marker of holistic face processing (Murphy et al., 2017; Rossion, 2013). To date, previous studies have yielded mixed findings; some authors have reported evidence of atypical composite effects in this population (Gauthier et al., 2009; Teunisse \& de Gelder, 2003), while others have described normal susceptibility (Nishimura et al., 2008; Ventura et al., 2018). The present findings of clear and comparable composite face effects in typical and ASD groups accord with those of Nishimura and colleagues (2008) and Ventura and Colleagues (2017). Contrary to the view that face perception deficits seen in ASD reflect aberrant holistic processing (Behrmann, Avidan, et al., 2006; Behrmann, Thomas, et al., 2006; Happé, 1999; Happé \& Frith, 2006), these results indicate that the integration processes measured by this illusion are intact in individuals with ASD.

At first glance, this conclusion appears to contradict the findings of Teunisse \& de Gelder (2003) and Gauthier and colleagues (2009). Close examination of these studies, however, suggests that neither provides strong evidence for diminished composite face effects in ASD. Although Teunisse \& de Gelder (2003) report that their ASD sample $(\mathrm{N}=17)$ failed to show a composite face effect, their composite task also failed to produce strong composite face effects in typical individuals. Typical children (aged 9-10 years) failed to show evidence of a composite effect, either in their RT or accuracy data, and typical adults showed a composite effect only in their RT data. The problems interpreting this result are compounded by the lack of a direct group comparison. The findings of Gauthier and Colleagues (2009) are curious insofar as the key difference between typical individuals and those with ASD $(\mathrm{N}=24)$ is seen in the misaligned condition. Although the autistic individuals were poorer at the matching task in all conditions, they showed the typical modulation by distractor congruence in the aligned condition. Unlike the typical group, however, the ASD group also showed a significant congruency effect in the misaligned condition. Rather than indicate diminished holistic face processing, this finding suggests that under some conditions, autistic individuals may process misaligned arrangements holistically, suggestive of a larger window of integration. 
The composite face effect appears to be a product of life-long exposure to the statistical regularities present in faces; for example, expressions of happiness are associated with characteristic patterns of change around the eyes and mouth, contingencies between so-called "eye-smile" and "mouth-smile". The visual system seems to use these regularities to set up strong predictions about the likely content of the target region of a composite arrangement, given the content of the task-irrelevant region. Our results suggest that autistic individuals (regardless of their level of alexithymia) are sensitive to these statistical regularities and are able to use this covariation to derive perceptual predictions.

Where observed, poor emotion recognition in autistic individuals may instead reflect difficulties interpreting the emotional content of expression percepts. The suggestion that expression recognition deficits in ASD are decisional - not apperceptive - accords with findings that autistic individuals who do exhibit emotion labeling impairments can still detect physical differences between facial expressions (Cook et al., 2013), and with the fact that affective deficits, where observed, extend to other types of affective stimuli including body movements and vocal cues (Heaton et al., 2012; Philip et al., 2010).

The present findings add to a growing body of evidence suggesting that individuals with ASD often process global configuration typically (Van der Hallen, Evers, Brewaeys, Van den Noortgate, \& Wagemans, 2015). For example, our findings align closely with a recent study that described typical integration of emotion cues from across the face and body in autistic individuals (Brewer et al., 2017). Similarly, many autistic individuals appear to derive accurate percepts of global motion (Manning, Tibber, Charman, Dakin, \& Pellicano, 2015), and exhibit typical susceptibility to simple visual illusions induced by context (Manning, Morgan, Allen, \& Pellicano, 2017). Individuals with ASD are also affected typically by the gestalt properties of to-be-copied target patterns (Smith, Kenny, Rudnicka, Briscoe, \& Pellicano, 2016). When instructed to identify the global configuration of hierarchical localglobal stimuli (e.g. 'Navon' letter arrays), recent evidence also suggests that individuals with ASD are often unimpaired (Koldewyn et al., 2013). Taken with the current findings, this evidence suggests that global processing abilities may not always be compromised in ASD.

\subsection{Implications for the composite face illusion}

There has been considerable debate about the functional significance of the composite face illusion (Murphy et al., 2017; Rossion, 2013). While some authors have claimed that the 
integration processes responsible for this illusion are closely related to face recognition ability (DeGutis, Wilmer, Mercado, \& Cohan, 2013; Richler et al., 2011), others have suggested there may be little or no relationship (Konar et al., 2010; Murphy \& Cook, 2017; Rezlescu et al., 2017; Wang et al., 2012). Typical composite face effects suggest that the locus of the face recognition difficulties seen in autism lies elsewhere in the face processing stream. Future research should continue to investigate the origin of these deficits, potentially aberrant face learning (Ipser et al., 2016) or atypical processing of facial motion (O'Brien et al., 2014).

Our results accord closely with recent findings that the majority of individuals with developmental prosopagnosia (a related neurodevelopmental disorder characterized by lifelong face recognition difficulties; Cook \& Biotti, 2016; Duchaine \& Nakayama, 2006b) also appear to show typical susceptibility to the composite face illusion (Biotti et al., 2017; Le Grand et al., 2006; Ulrich et al., 2017). Together, these findings support the view that the composite face illusion is a marker of extremely resilient face processing (Murphy et al., 2017), disrupted only by catastrophic damage to the face processing stream, such as that seen in adults who acquire prosopagnosia following brain injury (e.g., Busigny et al., 2014).

The present findings closely replicate those of Gray and colleagues (2017; Experiment 1). In both studies, stronger composite effects were observed as the strength of the emotion signal in the distractor increased. These results highlight the effect that emotion cues can have on the composite face illusion. While we failed to observe a composite effect in the $0 \%$ emotion condition (also reported by Gray and colleagues), we do not believe facial emotion is a necessary condition for the composite face illusion. The fact that the composite illusion alters individuals' perception of identity (Young et al., 1987), age (Hole \& George, 2011), and gender (Baudouin \& Humphreys, 2006) suggests that the covariation of facial structure is a source of perceptual prediction, independent of facial expression. Relative to the striking illusory effects induced by emotion cues, however, the distortion induced by facial structure alone may be relatively subtle. When emotional and neutral distractors are interleaved within blocks, the illusory distortion of target regions induced by high-emotion distractors may overshadow the illusory effects attributable to facial structure, causing observers to alter their decision criteria. As a result, instances of subtle structural distortion seen in the $0 \%$ emotion condition may not be sufficiently salient to elicit a 'different' response. 


\subsection{Conclusion}

In summary, we found that facial emotion cues modulate the strength of the composite face illusion to the same degree in typical individuals and those with ASD. The composite effects seen in the ASD group were quantitatively and qualitatively similar, suggestive of intact holistic processing. These findings indicate that autistic individuals are sensitive to the statistical regularities in facial expressions, despite that fact that some autistic individuals experience difficulty interpreting emotional expressions, and argue against the view that aberrant holistic processing is responsible for atypical face perception in this population. 


\section{Footnotes}

${ }^{1}$ We use the term 'autistic people' as research indicates that it is preferred by many individuals with ASD, as well as using terms preferred by clinicians, such as 'individuals with ASD’ (Kenny et al., 2016).

${ }^{2}$ Thirty typical observers were tested, however one participant was excluded having failed to follow task instructions.

${ }^{3}$ Under free-viewing conditions, some autistic people may spontaneously fixate on the eyeregion less often than controls. Importantly, however, individuals with autism (especially high-functioning cases) appear able to fixate eye-regions typically when instructed to do so (e.g. Shah, Bird, \& Cook, 2016). 


\section{Acknowledgements}

The authors are grateful to Hugh Kleinberg and Federica Biotti for their assistance with data collection.

\section{Conflicts of Interest}

The authors declare that they have no conflicts of interest. 


\section{References}

APA. (2013). Diagnostic and Statistical Manual of Mental Disorders (Fifth Edition).

Washington, DC: American Psychiatric Association.

Ashwin, C., Chapman, E., Colle, L., \& Baron-Cohen, S. (2006). Impaired recognition of negative basic emotions in autism: a test of the amygdala theory. Social Neuroscience, $1(3-4), 349-363$.

Bagby, R. M., Taylor, G. J., \& Parker, J. D. A. (1994). The twenty-item Toronto Alexithymia Scale-II. Convergent, discriminant, and concurrent validity. Journal of Psychosomatic Research, 38, 33-40.

Baron-Cohen, S., Wheelwright, S., \& Jolliffe, T. (1997). Is there a "language of the eyes"? Evidence from normal adults, and adults with autism or Asperger syndrome. Visual Cognition, 4(3), 311-331.

Baron-Cohen, S., Wheelwright, S., Skinner, R., Martin, J., \& Clubley, E. (2001). The autismspectrum quotient (AQ): evidence from Asperger syndrome/high-functioning autism, males and females, scientists and mathematicians. Journal of Autism and Developmental Disorders, 31(1), 5-17.

Baudouin, J. Y., \& Humphreys, G. W. (2006). Configural information in gender categorisation. Perception, 35(4), 531-540.

Behrmann, M., Avidan, G., Leonard, G. L., Kimchi, R., Luna, B., Humphreys, K., \& Minshew, N. (2006). Configural processing in autism and its relationship to face processing. Neuropsychologia, 44(1), 110-129.

Behrmann, M., Thomas, C., \& Humphreys, K. (2006). Seeing it differently: visual processing in autism. Trends in Cognitive Sciences, 10, 258-264. 
Berthoz, S., \& Hill, E. L. (2005). The validity of using self-reports to assess emotion regulation abilities in adults with autism spectrum disorder. European Psychiatry, 20, 291-298.

Biotti, F., Wu, E., Yang, H., Jiahui, G., Duchaine, B., \& Cook, R. (2017). Normal composite face effects in developmental prosopagnosia. Cortex, 95, 63-76.

Bird, G., \& Cook, R. (2013). Mixed emotions: the contribution of alexithymia to the emotional symptoms of autism. Translational Psychiatry, 3, e285.

Boucher, J., \& Lewis, V. (1992). Unfamiliar face recognition in relatively able autistic children. Journal of Child Psychology and Psychiatry, 33(5), 843-859.

Brewer, R., Biotti, F., Bird, G., \& Cook, R. (2017). Typical integration of emotion cues from bodies and faces in Autism Spectrum Disorder. Cognition, 165, 82-87.

Busigny, T., Van Belle, G., Jemel, B., Hosein, A., Joubert, S., \& Rossion, B. (2014). Facespecific impairment in holistic perception following focal lesion of the right anterior temporal lobe. Neuropsychologia, 56, 312-333.

Calder, A. J., Young, A. W., Keane, J., \& Dean, M. (2000). Configural information in facial expression perception. Journal of Experimental Psychology: Human Perception and Performance, 26(2), 527-551.

Cook, R., Aichelburg, C., \& Johnston, A. (2015). Illusory feature slowing: evidence for perceptual models of global facial change. Psychological Science, 26(4), 512-517.

Cook, R., \& Biotti, F. (2016). Developmental prosopagnosia. Current Biology, 26(8), R312R313.

Cook, R., Brewer, R., Shah, P., \& Bird, G. (2013). Alexithymia, not autism, predicts poor recognition of emotional facial expressions. Psychological Science, 24, 723-732. 
DeGutis, J., Wilmer, J., Mercado, R. J., \& Cohan, S. (2013). Using regression to measure holistic face processing reveals a strong link with face recognition ability. Cognition, $126(1), 87-100$.

Duchaine, B., \& Nakayama, K. (2006a). The Cambridge Face Memory Test: results for neurologically intact individuals and an investigation of its validity using inverted face stimuli and prosopagnosic participants. Neuropsychologia, 44(4), 576-585.

Duchaine, B., \& Nakayama, K. (2006b). Developmental prosopagnosia: a window to contentspecific face processing. Current Opinion in Neurobiology, 16, 166-173.

Farah, M. J., Wilson, K. D., Drain, M., \& Tanaka, J. N. (1998). What is" special" about face perception? . Psychological Review, 105(3), 482-498.

Gauthier, I., Klaiman, C., \& Schultz, R. T. (2009). Face composite effects reveal abnormal face processing in Autism spectrum disorders. Vision Research, 49(4), 470-478.

Gray, K. L. H., Bird, G., \& Cook, R. (2017). Robust associations between the 20-Item Prosopagnosia Index and the Cambridge Face Memory Test in the general population. Royal Society Open Science, 4(3), 160923.

Gray, K. L. H., Murphy, J., Marsh, J., \& Cook, R. (2017). Modulation of the composite face effect by unintended emotion cues. Royal Society Open Science, 4(4), 160867.

Grynberg, D., Chang, B., Corneille, O., Maurage, P., Vermeulen, N., Berthoz, S., \& Luminet, O. (2012). Alexithymia and the processing of emotional facial expressions (EFEs): systematic review, unanswered questions and further perspectives. PLoS One, 7(8), e42429.

Happé, F. (1996). Studying weak central coherence at low levels: children with autism do not succumb to visual illusions. Journal of Child Psychology and Psychiatry, 37, 873877.

Happé, F. (1999). Autism: cognitive deficit or cognitive style? Trends in Cognitive Sciences, $3,216-222$. 
Happé, F., \& Frith, U. (2006). The weak coherence account: detail-focused cognitive style in autism spectrum disorders. Journal of Autism and Developmental Disorders, 36, 5-25.

Harms, M. B., Martin, A., \& Wallace, G. L. (2010). Facial emotion recognition in autism spectrum disorders: a review of behavioral and neuroimaging studies. Neuropsychological Review, 20(3), 290-322.

Heaton, P., Reichenbacher, L., Sauter, D., Allen, R., Scott, S., \& Hill, E. (2012). Measuring the effects of alexithymia on perception of emotional vocalizations in autistic spectrum disorder and typical development. Psychological Medicine, 42(11), 24532459.

Hedley, D., Brewer, N., \& Young, R. (2011). Face recognition performance of individuals with Asperger syndrome on the Cambridge Face Memory Test. Autism Research, $4(6), 449-455$.

Hill, E., Berthoz, S., \& Frith, U. (2004). Brief report: Cognitive processing of own emotions in individuals with autistic spectrum disorder and in their relatives. Journal of Autism and Developmental Disorders, 34, 229-235.

Hole, G. (1994). Configurational factors in the perception of unfamiliar faces. Perception,, $23(1), 65-74$.

Hole, G., \& George, P. (2011). Evidence for holistic processing of facial age. Visual Cognition, 19(5), 585-615.

Humphreys, K., Minshew, N., Leonard, G. L., \& Behrmann, M. (2007). A fine-grained analysis of facial expression processing in high-functioning adults with autism. Neuropsychologia, 45(4), 685-695.

Ipser, A., Ring, M., Murphy, J., Gaigg, S. B., \& Cook, R. (2016). Similar exemplar pooling processes underlie the learning of facial identity and handwriting style: Evidence from typical observers and individuals with Autism. Neuropsychologia, 85, 169-176. 
Jack, R. E., Garrod, O. G. B., \& Schyns, P. G. (2014). Dynamic facial expressions of emotion transmit an evolving hierarchy of signals over time. Current Biology, 24(2), 187-192.

Johnston, A. (2011). Is dynamic face perception primary? In C. Curio, M. Giese, \& H. H. Bulthoff (Eds.), Dynamic Faces: Insights from Experiments and Computation. Cambridge, MA, USA: MIT Press.

Kenny, L., Hattersley, C., Molins, B., Buckley, C., Povey, C., \& Pellicano, E. (2016). Which terms should be used to describe autism? Perspectives from the UK autism community. Autism, 20(4), 442-462.

Klin, A., Schultz, S., \& Jones, W. (2015). Social visual engagement in infants and toddlers with autism: Early developmental transitions and a model of pathogenesis. Neuroscience and Biobehavioral Reviews, 50, 189-203.

Koldewyn, K., Jiang, Y. V., Weigelt, S., \& Kanwisher, N. (2013). Global/local processing in autism: not a disability, but a disinclination. Journal of Autism and Developmental Disorders, 43(10), 2329-2340.

Konar, Y., Bennett, P. J., \& Sekuler, A. B. (2010). Holistic processing is not correlated with face-identification accuracy. Psychological Science, 21(1), 38-43.

Langner, O., Dotsch, R., Bijlstra, G., Wigboldus, D. H. J., Hawk, S. T., \& van Knippenberg, A. (2010). Presentation and validation of the Radboud Faces Database. Cognition \& Emotion, 24(8), 1377-1388.

Le Grand, R., Cooper, P. A., Mondloch, C. J., Lewis, T. L., Sagiv, N., de Gelder, B., \& Maurer, D. (2006). What aspects of face processing are impaired in developmental prosopagnosia? Brain and Cognition, 61(2), 139-158.

Le Grand, R., Mondloch, C. J., Maurer, D., \& Brent, H. P. (2004). Impairment in holistic face processing following early visual deprivation. Psychological Science, 15(11), 762768. 
Lord, C., Risi, S., Lambrecht, L., Cook, E. H., Leventhal, B. L., DiLavore, P. C., . . Rutter, M. (2000). The autism diagnostic observation schedule-generic: a standard measure of social and communication deficits associated with the spectrum of autism. Journal of Autism and Developmental Disorders, 30, 205-223.

Manning, C., Morgan, M. J., Allen, C. T. W., \& Pellicano, E. (2017). Susceptibility to Ebbinghaus and Muller-Lyer illusions in autistic children: a comparison of three different methods. Molecular Autism, 8, 16.

Manning, C., Tibber, M. S., Charman, T., Dakin, S. C., \& Pellicano, E. (2015). Enhanced integration of motion information in children with autism. Journal of Neuroscience, 35(18), 6979-6986.

Maurer, D., Le Grand, R., \& Mondloch, C. J. (2002). The many faces of configural processing. Trends in Cognitive Sciences, 6(6), 255-260.

McKone, E., \& Yovel, G. (2009). Why does picture-plane inversion sometimes dissociate the perception of features and spacing in faces, and sometimes not? Toward a new theory of holistic processing. Psychonomic Bulletin \& Review, 16(5), 778-797.

Murphy, J., \& Cook, R. (2017). Revealing the mechanisms of human face perception using dynamic apertures. Cognition, 169, 25-35.

Murphy, J., Gray, K. L. H., \& Cook, R. (2017). The composite face illusion. Psychonomic Bulletin \& Review, 24(2), 245-261.

Nemiah, J. C., Freyberger, H. J., \& Sifneos, P. E. (1976). Alexithymia: a view of the psychosomatic process. In O. W. Hill (Ed.), Modern Trends in Psychosomatic Medicine. London, UK: Butterworths.

Nishimura, M., Rutherford, M. D., \& Maurer, D. (2008). Converging evidence of configural processing of faces in high-functioning adults with autism spectrum disorders. Visual Cognition, 16, 859-891. 
O'Brien, J., Spencer, J., Girges, C., Johnston, A., \& Hill, H. (2014). Impaired perception of facial motion in autism spectrum disorder. PLoS One, 9(7), e102173.

Oakley, B. F. M., Brewer, R., Bird, G., \& Catmur, C. (2016). Theory of mind is not theory of emotion: A cautionary note on the Reading the Mind in the Eyes Test. Journal of Abnormal Psychology, 125(6), 818-823.

Philip, R. C., Whalley, H. C., Stanfield, A. C., Sprengelmeyer, R., Santos, I. M., Young, A. W., .. . Hall, J. (2010). Deficits in facial, body movement and vocal emotional processing in autism spectrum disorders. Psychological Medicine, 40(11), 1919-1929.

Piepers, D. W., \& Robbins, R. A. (2013). A review and clarification of the terms "holistic," "configural," and "relational" in the face perception literature. Frontiers in Psychology, 3(559), 1-11.

Poquérusse, J., Pastore, L., Dellantonio, S., \& Esposito, G. (2018). Alexithymia and autism spectrum disorder: a complex relationship. Frontiers in Psychology, 9(1196).

Rezlescu, C., Susilo, T., Wilmer, J. B., \& Caramazza, A. (2017). The inversion, part-whole, and composite effects reflect distinct perceptual mechanisms with varied relationship to face recognition. Journal of Experimental Psychology: Human Perception and Performance, 43(12), 1961-1973.

Richler, J. J., Cheung, O. S., \& Gauthier, I. (2011). Holistic processing predicts face recognition. Psychological Science, 22(4), 464-471.

Ropar, D., \& Mitchell, P. (2001). Susceptibility to illusions and performance on visuospatial tasks in individuals with autism. Journal of Child Psychology and Psychiatry, 42, 539-549.

Rossion, B. (2013). The composite face illusion: A whole window into our understanding of holistic face perception. Visual Cognition, 21(2), 139-253.

Rossion, B., \& Retter, T. L. (2015). Holistic face perception: Mind the gap! Visual Cognition, 23(3), 379-398. 
Schultz, R. T. (2005). Developmental deficits in social perception in autism: the role of the amygdala and fusiform face area. International Journal of Developmental Neuroscience, 23(2-3), 125-141.

Shah, A., \& Frith, U. (1983). An islet of ability in autistic children: A research note. Journal of Child Psychology and Psychiatry, 24, 613-620.

Shah, P., Bird, G., \& Cook, R. (2016). Face processing in autism: Reduced integration of cross-feature dynamics. Cortex, 75, 113-119.

Shah, P., Gaule, A., Bird, G., \& Cook, R. (2013). Robust orienting to protofacial stimuli in autism. Current Biology, 23(24), R1087-1088.

Shah, P., Gaule, A., Sowden, S., Bird, G., \& Cook, R. (2015). The 20-item prosopagnosia index (PI20): a self-report instrument for identifying developmental prosopagnosia. Royal Society Open Science, 2(6), 140343.

Simmons, D. R., Robertson, A. E., McKay, L. S., Toal, E., McAleer, P., \& Pollick, F. E. (2009). Vision in autism spectrum disorders. Vision Research, 49, 2705-2739.

Smith, A. D., Kenny, L., Rudnicka, A., Briscoe, J., \& Pellicano, E. (2016). Drawing firmer conclusions: Autistic children show no evidence of a local processing bias in a controlled copying task. Journal of Autism and Developmental Disorders, 46(11), 3481-3492.

Teunisse, J. P., \& de Gelder, B. (2003). Face processing in adolescents with autistic disorder: the inversion and composite effects. Brain and Cognition, 52(3), 285-294.

Ulrich, P. I., Wilkinson, D. T., Ferguson, H. J., Smith, L. J., Bindemann, M., Johnston, R. A., \& Schmalzl, L. (2017). Perceptual and memorial contributions to developmental prosopagnosia. Quarterly Journal of Experimental Psychology, 70(2), 298-315.

Van der Hallen, R., Evers, K., Brewaeys, K., Van den Noortgate, W., \& Wagemans, J. (2015). Global processing takes time: A meta-analysis on local-global visual processing in ASD. Psychological Bulletin, 141(3), 549-573. 
Ventura, P., Carmo, J. C., Souza, C., Martins, F., Leite, I., \& Pinho, S. (2018). Holistic processing of faces is intact in adults with autism spectrum disorder. Visual Cognition, 26(1), 13-24.

Wallace, S., Coleman, M., \& Bailey, A. (2008a). Face and object processing in autism spectrum disorders. Autism Research, 1(1), 43-51.

Wallace, S., Coleman, M., \& Bailey, A. (2008b). An investigation of basic facial expression recognition in autism spectrum disorders. Cognition \& Emotion, 22(7), 1353-1380.

Wang, R., Li, J., Fang, H., Tian, M., \& Liu, J. (2012). Individual differences in holistic processing predict face recognition ability. Psychological Science, 23(2), 169-177.

Webb, S. J., Neuhaus, E., \& Faja, S. (2016). Face perception and learning in autism spectrum disorders. Quarterly Journal of Experimental Psychology, 70(5), 970-986.

Wechsler, D. (1997). Wechsler Adult Intelligence Scale (3rd Edition). San Antonio, TX: Psychological Corporation.

Wechsler, D. (1999). Wechsler Abbreviated Scale of Intelligence. San Antonio, TX: Psychological Corporation.

Weigelt, S., Koldewyn, K., \& Kanwisher, N. (2012). Face identity recognition in autism spectrum disorders: A review of behavioral studies. Neuroscience and Biobehavioral Reviews, 36(3), 1060-1084.

Young, A. W., Hellawell, D., \& Hay, D. C. (1987). Configurational information in face perception. Perception, 16(6), 747-759. 


\section{Figure legends}

Figure 1

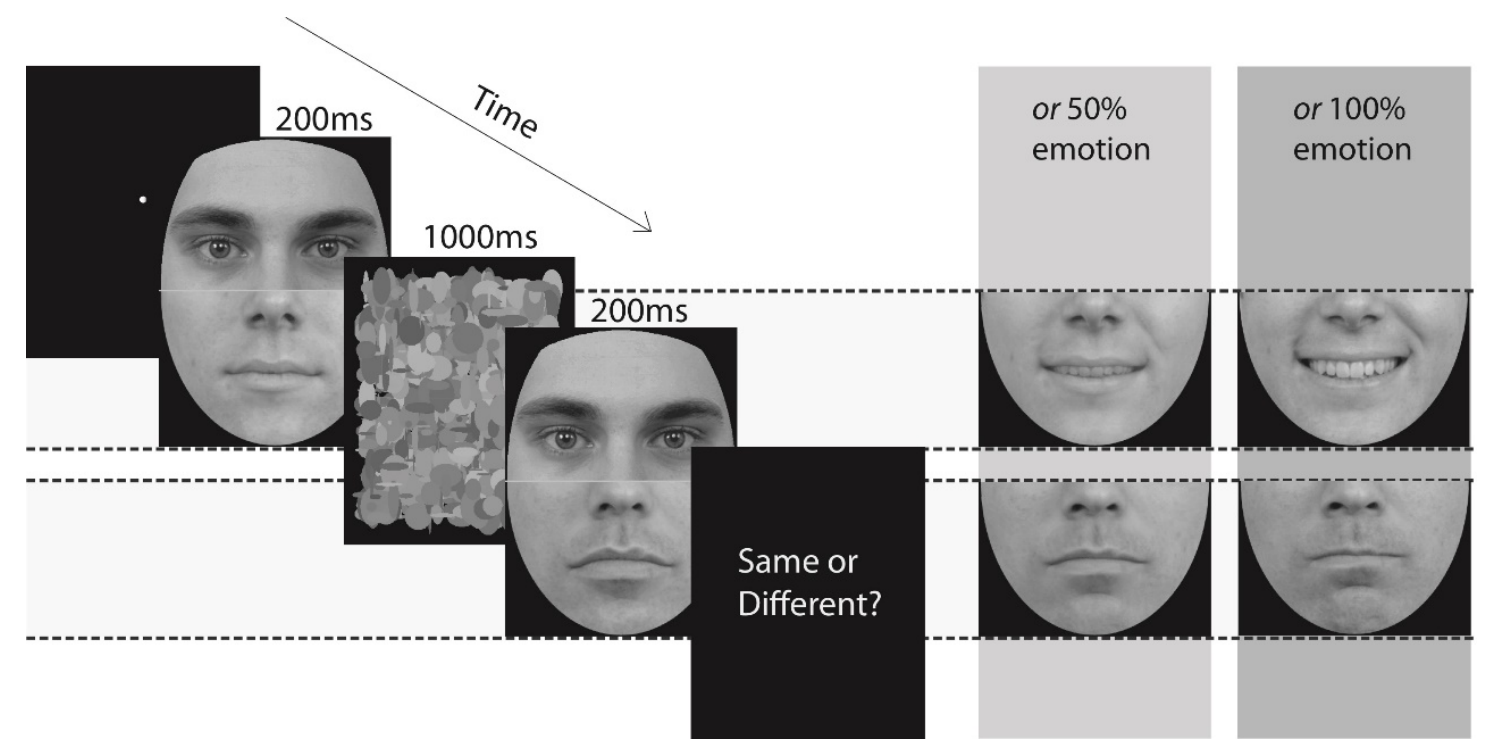

Figure 1. The incidental emotion composite face procedure. Image morphing is used to vary the emotion content of the distractor region. As the strength of the emotion signal increases, the distractor region induces greater illusory distortion of the target region, and participants' ability to discriminate the target regions decreases. 
Figure 2
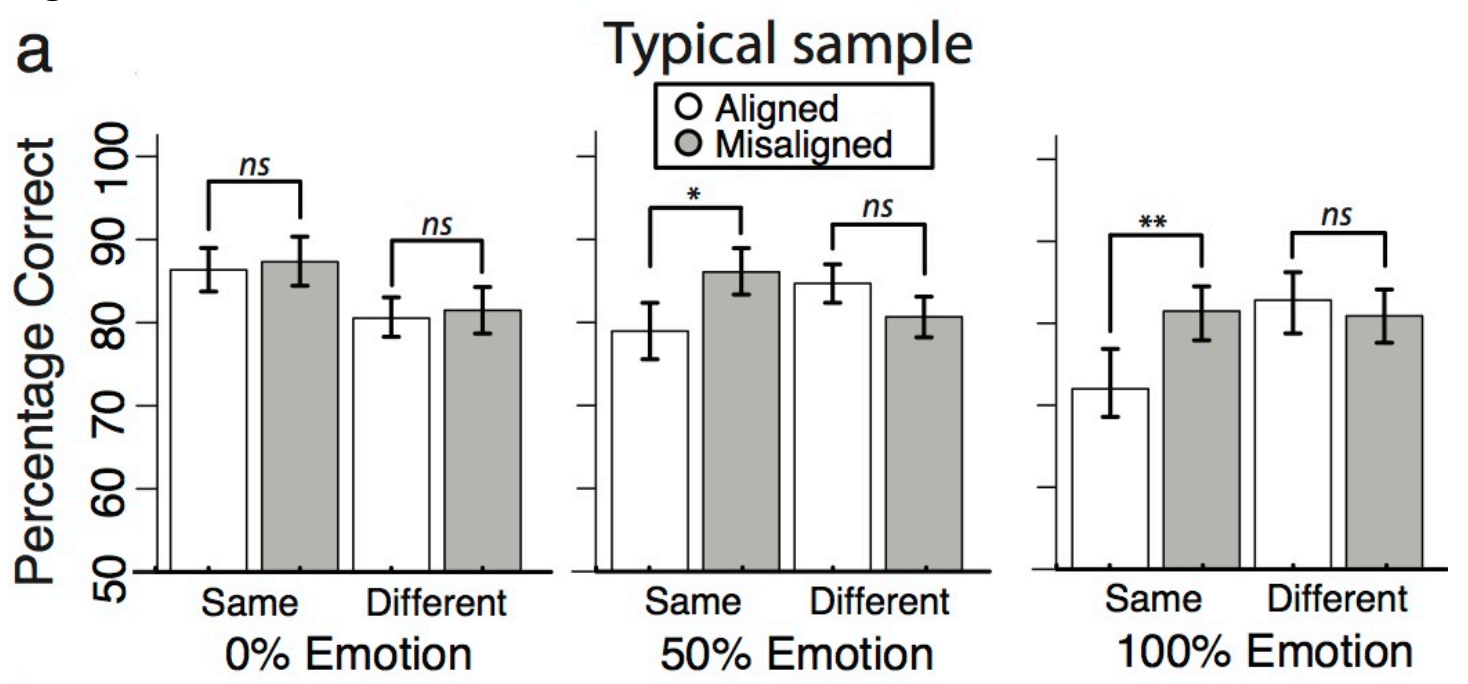

$\mathrm{b}$
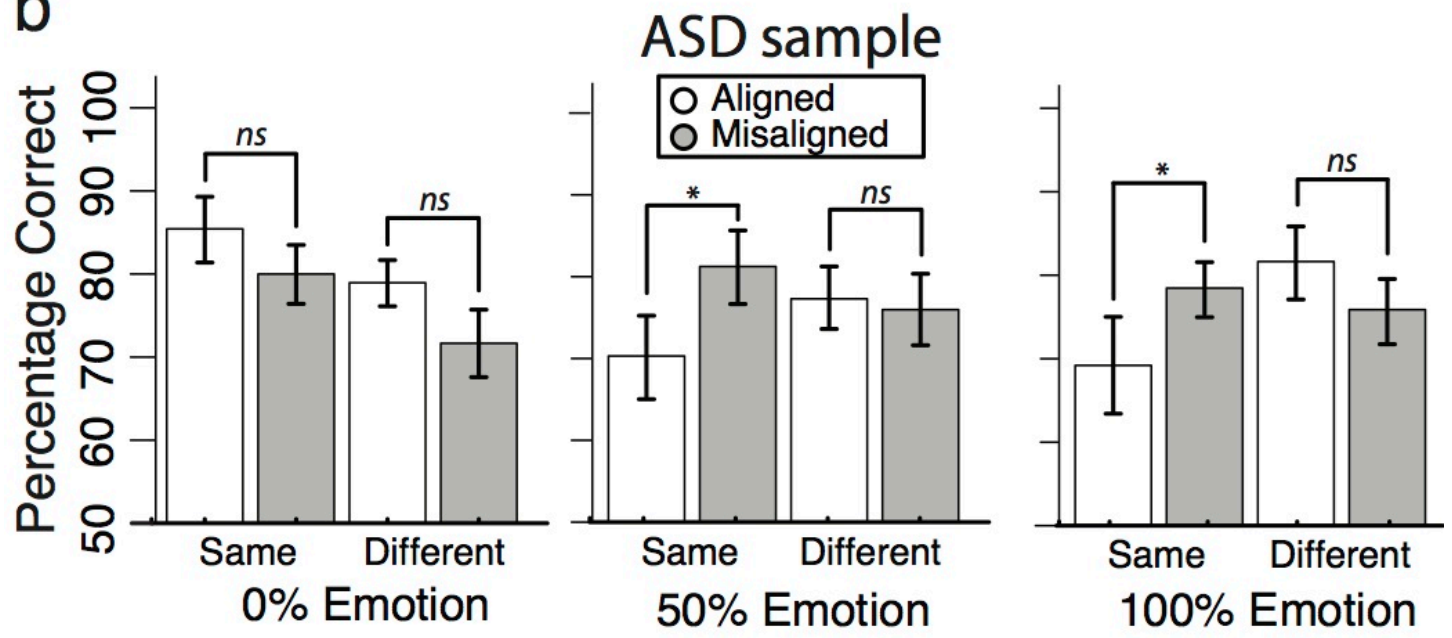

Figure 2. Accuracy scores in the aligned and misaligned conditions on trials when target halves were the same and different for (a) typical and (b) ASD samples. Error bars indicate \pm 1 SEM. $*$ denotes $p<.05$, ** denotes $p<.01$. 
Table 1. Demographic and diagnostic information for all participants in the ASD group.

\begin{tabular}{|c|c|c|c|c|c|c|c|c|c|c|c|}
\hline & $\begin{array}{l}\text { ADOS } \\
\text { Score }\end{array}$ & $\begin{array}{c}\text { ADOS } \\
\text { Classification }\end{array}$ & Sex & Age & $\mathbf{A Q}$ & $\begin{array}{c}\text { Full-Scale } \\
\text { IQ } \\
\end{array}$ & TAS-20 & CFMT & PI20 & $\begin{array}{c}\text { Sadness- } \\
\text { fear }\end{array}$ & $\begin{array}{l}\text { Disgust- } \\
\text { anger }\end{array}$ \\
\hline 1 & 7 & Autism Spectrum & M & 38 & 17 & 125 & 27 & $65 \%$ & 56 & $8 \%$ & $7 \%$ \\
\hline 2 & 10 & Autism & $\mathrm{F}$ & 22 & 20 & 121 & 44 & $60 \%$ & 60 & $9 \%$ & $5 \%$ \\
\hline 3 & 11 & Autism & M & 42 & 33 & 117 & 36 & $83 \%$ & 63 & $1 \%$ & $22 \%$ \\
\hline 4 & 8 & Autism Spectrum & M & 18 & 21 & 107 & 73 & $51 \%$ & 40 & $6 \%$ & $7 \%$ \\
\hline 5 & 15 & Autism & $\mathrm{F}$ & 52 & 45 & 116 & 69 & $78 \%$ & 32 & $10 \%$ & $12 \%$ \\
\hline 6 & 11 & Autism & M & 31 & 37 & 118 & 38 & $54 \%$ & 46 & $7 \%$ & $6 \%$ \\
\hline 7 & 11 & Autism & M & 37 & 35 & 99 & 56 & $86 \%$ & 33 & - & - \\
\hline 8 & 10 & Autism & M & 35 & 46 & 112 & 54 & $88 \%$ & 36 & $1 \%$ & $1 \%$ \\
\hline 9 & 14 & Autism & M & 38 & 23 & 78 & 56 & $63 \%$ & - & - & - \\
\hline 10 & 7 & Autism Spectrum & M & 61 & 45 & 132 & 61 & $65 \%$ & 65 & $1 \%$ & $1 \%$ \\
\hline 11 & 9 & Autism Spectrum & M & 33 & 35 & 128 & 60 & $82 \%$ & 45 & $18 \%$ & $52 \%$ \\
\hline 12 & 9 & Autism Spectrum & M & 25 & 39 & 133 & 61 & $61 \%$ & 54 & $16 \%$ & $37 \%$ \\
\hline 13 & 8 & Autism Spectrum & $\mathrm{F}$ & 21 & 46 & 93 & 81 & $74 \%$ & - & $17 \%$ & $37 \%$ \\
\hline 14 & 9 & Autism & M & 19 & 31 & 92 & 60 & - & - & $21 \%$ & $11 \%$ \\
\hline 15 & 10 & Autism & M & 21 & 35 & 107 & 72 & $72 \%$ & 53 & $7 \%$ & $18 \%$ \\
\hline 16 & 14 & Autism & M & 49 & 50 & 121 & 84 & $46 \%$ & 79 & $8 \%$ & $10 \%$ \\
\hline 17 & 10 & Autism & M & 33 & 41 & 122 & 67 & $53 \%$ & 60 & - & - \\
\hline 18 & 7 & Autism Spectrum & $\mathrm{M}$ & 38 & 40 & 116 & 71 & $78 \%$ & 50 & $4 \%$ & $7 \%$ \\
\hline 19 & 12 & Autism & M & 31 & 48 & 107 & 64 & $54 \%$ & 60 & $13 \%$ & $12 \%$ \\
\hline 20 & 8 & Autism Spectrum & M & 35 & 36 & 108 & 72 & $49 \%$ & 71 & $9 \%$ & $7 \%$ \\
\hline \multicolumn{4}{|c|}{$\begin{array}{l}\text { ASD group mean } \\
\text { (SD) }\end{array}$} & $\begin{array}{c}33.9 \\
(11.4) \\
\end{array}$ & $\begin{array}{l}36.2 \\
(9.7) \\
\end{array}$ & $\begin{array}{l}112.6 \\
(14.1) \\
\end{array}$ & $\begin{array}{c}60.3 \\
(14.8) \\
\end{array}$ & $\begin{array}{c}66.4 \\
(13.5) \\
\end{array}$ & $\begin{array}{c}53.1 \\
(13.3) \\
\end{array}$ & $\begin{array}{c}.09 \\
(.06)\end{array}$ & $\begin{array}{l}.15 \\
(.14)\end{array}$ \\
\hline
\end{tabular}


Typical group mean

$35.0 \quad 17.7$

109.4

(12.2)

41.07 (60.30)

$$
\text { (SD) }
$$

(10.2) (5.9) 
Table 2. Main and interaction effects in the Target Type (same, different) $\times$ Alignment (aligned, misaligned) $\times$ Emotion Intensity $(0 \%, 50 \%, 100 \%) \times$ Group (ASD, typical) ANOVA.

\begin{tabular}{lccc}
\hline \multicolumn{1}{c}{ Effect } & $F$ & $p$ & $\eta^{2}$ \\
\hline Main effect of Target Type & .002 & .968 & $<.001$ \\
Main effect of Alignment & 1.58 & .214 & .033 \\
Main effect of Emotion Intensity & 6.23 & .005 & .117 \\
Main effect of Group & 2.48 & .122 & .050 \\
\hline Target Type $\times$ Alignment & 12.82 & .001 & .214 \\
Target Type $\times$ Emotion Intensity & 12.19 & $<.001$ & .206 \\
Target Type $\times$ Group & .018 & .894 & $<.001$ \\
Alignment $\times$ Emotion Intensity & 5.70 & .005 & .108 \\
Alignment $\times$ Group & 1.04 & .313 & .022 \\
Emotion Intensity $\times$ Group & 1.05 & .353 & .022 \\
\hline Target Type $\times$ Alignment $\times$ Emotion Intensity & 8.77 & $<.001$ & .157 \\
Target Type $\times$ Alignment $\times$ Group & .17 & .681 & .004 \\
Target Type $\times$ Emotion Intensity $\times$ Group & .223 & .797 & .005 \\
Alignment $\times$ Emotion Intensity $\times$ Group & 3.72 & .030 & .073 \\
\hline Target Type $\times$ Alignment $\times$ Emotion Intensity $\times$ Group & .005 & .995 & $<.001$
\end{tabular}




\section{Face perception in autism spectrum disorder: Modulation of holistic processing by facial emotion}

\section{Rebecca Brewer, Geoffrey Bird, Katie L. H. Gray, Richard Cook \\ Supplementary analyses}

A number of approaches have been taken in order to estimate the magnitude of the face composite effect, for use in individual differences analyses. Below we describe a number of methods that can be used to quantify the composite effect, and report the relationship between each of these estimates and a) performance on the emotion recognition tasks, b) PI20 scores, c) CFMT scores (all in the ASD sample), and d) alexithymia (in the full sample and the ASD and typical groups separately).

\section{Method 1: Same misaligned - same aligned}

Some authors have estimated the magnitude of the composite effect by taking the difference between accuracy scores in the misaligned and aligned trials, specifically on trials where the two upper halves were the same (e.g. Heering, Houthuys, \& Rossion, 2007; Le Grand et al., 2006; Michel, Rossion, Han, Chung, \& Caldara, 2006). Using this variable, we found no relationship between the magnitude of the composite effect measure and any individual difference measure (see table S1).

Table S1. Correlations between magnitude of the composite effect estimated by same misaligned accuracy - same aligned accuracy and PI20 scores, CFMT scores, emotion recognition task performance, and alexithymia.

\begin{tabular}{lllll} 
Variable & Sample & Emotion Level & $\boldsymbol{r}$ & $\boldsymbol{p}$ \\
\hline PI20 score & ASD group & $0 \%$ & -.24 & .344 \\
& & $50 \%$ & -.07 & .791 \\
& & $100 \%$ & -.14 & .603 \\
\hline CFMT score & ASD group & $0 \%$ & .30 & .216 \\
& & $50 \%$ & .06 & .822 \\
& & $100 \%$ & -.41 & .081 \\
\hline Sadness-fear & ASD group & $0 \%$ & -.38 & .133 \\
decision noise & & $50 \%$ & -.11 & .689 \\
& & $100 \%$ & .17 & .516 \\
\hline Disgust-anger & ASD group & $0 \%$ & -.18 & .485 \\
decision noise & & $50 \%$ & -.25 & .329 \\
& & $100 \%$ & .05 & .841 \\
\hline TAS-20 score & Full sample & $0 \%$ & -.09 & .551 \\
& & $50 \%$ & .17 & .244 \\
& & $100 \%$ & .08 & .575 \\
\cline { 2 - 5 } & ASD group & $0 \%$ & .09 & .704 \\
& & $50 \%$ & .07 & .776 \\
& & $100 \%$ & .19 & .413 \\
\cline { 2 - 5 } & & $0 \%$ & .01 & .968 \\
& TD group & $0 \%$ & .22 & .252 \\
& & $50 \%$ & .05 & .791
\end{tabular}




\section{Method 2: Normalised composite effect}

Others have estimated the composite effect magnitude using a 'normalised composite effect', calculated as the difference between accuracy scores in the aligned and misaligned conditions, divided by the sum of these accuracy scores, again only using trials where the targets are the same (De Heering \& Rossion, 2008; Wang, Li, Fang, Tian, \& Liu, 2012). This is calculated using the equation (misaligned same - aligned same)/ (misaligned same + aligned same). Using this variable, we again found no relationship with any of the individual difference variables (see table S2).

Table S2. Correlations between normalised composite effect and PI20 scores, CFMT scores, emotion recognition task performance, and alexithymia.

\begin{tabular}{|c|c|c|c|c|}
\hline Variable & Sample & Emotion Level & $r$ & $p$ \\
\hline \multirow[t]{3}{*}{ PI20 score } & ASD group & $0 \%$ & -.26 & .314 \\
\hline & & $50 \%$ & -.07 & .783 \\
\hline & & $100 \%$ & -.09 & .727 \\
\hline \multirow[t]{3}{*}{ CFMT score } & ASD group & $0 \%$ & .31 & .204 \\
\hline & & $50 \%$ & $<.01$ & .987 \\
\hline & & $100 \%$ & -.37 & .120 \\
\hline \multirow{3}{*}{$\begin{array}{l}\text { Sadness-fear } \\
\text { decision noise }\end{array}$} & ASD group & $0 \%$ & -.33 & .197 \\
\hline & & $50 \%$ & $<.01$ & .995 \\
\hline & & $100 \%$ & .21 & .429 \\
\hline \multirow{3}{*}{$\begin{array}{l}\text { Disgust-anger } \\
\text { decision noise }\end{array}$} & ASD group & $0 \%$ & -.15 & .577 \\
\hline & & $50 \%$ & -.22 & .398 \\
\hline & & $100 \%$ & .10 & .694 \\
\hline \multirow[t]{9}{*}{ TAS-20 score } & Full sample & $0 \%$ & -.08 & .575 \\
\hline & & $50 \%$ & .17 & .248 \\
\hline & & $100 \%$ & .10 & .506 \\
\hline & ASD group & $0 \%$ & .13 & .592 \\
\hline & & $50 \%$ & .05 & .850 \\
\hline & & $100 \%$ & .22 & .355 \\
\hline & TD group & $0 \%$ & .06 & .758 \\
\hline & & $50 \%$ & .26 & .191 \\
\hline & & $100 \%$ & .06 & .765 \\
\hline
\end{tabular}

\section{Method 3: Difference of differences}

An alternative way to estimate the size of the composite effect, which is closer to the ideal Alignment $\times$ Target Type $\times$ Emotion Intensity interaction, is to calculate the alignment*target type interaction in each individual and investigate this at each level of emotion intensity. This was calculated by taking a 'difference of differences' score for each individual, calculated using the equation (misaligned different - aligned different) - (misaligned same - aligned same). In line with the previous two analyses, there was no relationship with individual difference variables (see table S3). 
Table S3. Correlations between magnitude of the composite effect estimated by the difference of differences measure and PI20 scores, CFMT scores, emotion recognition task performance, and alexithymia.

\begin{tabular}{lllll} 
Variable & Sample & Emotion Level & $\boldsymbol{r}$ & $\boldsymbol{p}$ \\
\hline PI20 score & ASD group & $0 \%$ & .25 & .336 \\
& & $50 \%$ & .16 & .540 \\
& & $100 \%$ & .18 & .481 \\
\hline CFMT score & ASD group & $0 \%$ & -.21 & .384 \\
& & $50 \%$ & .19 & .446 \\
& & $100 \%$ & .41 & .078 \\
\hline Sadness-fear & ASD group & $0 \%$ & -.03 & .897 \\
decision noise & & $50 \%$ & -.11 & .674 \\
& & $100 \%$ & -.14 & .595 \\
\hline Disgust-anger & ASD group & $0 \%$ & .17 & .515 \\
decision noise & & $50 \%$ & .21 & .424 \\
& & $100 \%$ & -.12 & .661 \\
\hline TAS-20 score & Full sample & $0 \%$ & -.19 & .191 \\
& & $50 \%$ & .17 & .249 \\
& & $100 \%$ & -.19 & .198 \\
\cline { 2 - 5 } & ASD group & $0 \%$ & -.16 & .498 \\
& & $50 \%$ & -.23 & .340 \\
& & $100 \%$ & -.34 & .137 \\
\cline { 2 - 5 } & TD group & $0 \%$ & -.28 & .150 \\
& & $50 \%$ & .13 & .520 \\
& & $100 \%$ & -.04 & .834
\end{tabular}

\section{Supplementary References}

de Heering, A., Houthuys, S., \& Rossion, B. (2007). Holistic face processing is mature at 4 years of age : Evidence from the composite face effect. Journal of Experimental Child Psychology, 96, 57-70.

de Heering, A., \& Rossion, B. (2008). Prolonged Visual Experience in Adulthood Modulates Holistic Face Perception. PLoS ONE, 3(5), e2317.

Le Grand, R., Cooper, P. A., Mondloch, C. J., Lewis, T. L., Sagiv, N., Gelder, B. De, \& Maurer, D. (2006). What aspects of face processing are impaired in developmental prosopagnosia ? Brain and Cognition, 61, 139-158.

Michel, C., Rossion, B., Han, J., Chung, C.-S., \& Caldara, R. (2006). Holistic Processing Is Finely Tuned for Faces of One's Own Race. Psychological Science, 17(7), 608-615.

Wang, R., Li, J., Fang, H., Tian, M., \& Liu, J. (2012). Individual differences in holistic processing predict face recognition ability. Psychological Science, 23(2), 169-77. 